\section{GOVERNMENT RESEARCH IN} AUSTRALIA

\section{FIRST ANNUAL REPORT OF THE COMMONWEALTH SCIENTIFIC AND INDUSTRIAL RESEARCH ORGANISATION}

$\mathrm{T}$

HE first annual report of the Commonwealth of Australia Scientific and Industrial Research Organisation* covers the year ended June 30, 1949, and records that the work of the old Council for Scientific and Industrial Research is being carried on without any break, despite the administrative changes whereby the Organisation is governed by an executive of five persons, with an advisory council, in place of the former governing body (see Nature, April 22, p. 638 ).

The Division of Aeronautics was transferred to the Department of Supply and Development in February 1949. Stress is again laid on the development of North Australia, and investigation of the potentialities is not limited to agricultural development. In co-operation with the Queensland Government, a station has been established on Thursday Island at which research on oyster culture will be conducted, and from this base a research vessel of the Division of Fisheries will survey the northern coasts for occurrences of marketable fish.

In developing the programme of wool research, the main difficulties have been those associated with the provision of suitable buildings and field stations, but the Council of the 'Textile College of the Garden Institute of Technology has assisted the work on wool textiles by providing laboratory and office accommodation. The Coal Survey Section, formed to survey the physical and chemical properties of Australian coals, has been renamed the Coal Research Section, and a site for its headquarters laboratory has been acquired in Sydney. A Wild Life Survey Section was established early in 1949 to handle the comprehensive biological investigation of rabbit control and any other problem relating to native or introduced mammals or birds demanding study.

The general body of the report is arranged by subjects rather than by Divisions, as in previous years. Shortage of trained staff has hampered the work on soils. Stress is laid on the work on seasonal changes in water content under houses and on work on Rhizobium, the genus responsible for nodulation of leguminous plants. Study of the problem of the decline of Wimmera rye grass in rye grass - subterranean clover pasture has continued, as well as field trials and pot-culture trials on the nutrient requirements of pastures on soils on the southern tablelands of New South Wales. The effects of plant. growth regulating substances on perennial weeds have been investigated with promising results, while fruit investigations have included a field survey of the occurrence of gummosis of apricots. Yellowdwarf disease of tobacco was observed for the first time in north Queensland in 1948, while field trials of varieties of potato resistant to common scab continued. Investigation of the mineral nutrition of plants in the Ninety-mile Plain, South Australia, has been extended.

Work on nutrition has been largely confined to studies of the nutritional physiology of the sheep and

* Commonwealth of Australia: Commonwealth Scientific and Industrial Research Organisation. First Annual Keport for the Year ending 30th June, 1949. Pp. vi +273 . (Melbourne C. the influence of nutrition on wool production. Some work was done on the toxicity to sheep of large rations of wheat and on vitamin $D$ supplements, on the physiology of reproduction and the biology of skin and wool growth. Cattle tick and sheep blowfly continued to receive attention, and the Division of Entomology reports progress in various studies of insect physiology and toxicology, biological control, the control of locusts and grasshoppers, the distribution of the pasture cockchafer and control of the red-legged earth mite. The activities of the Division of Fisheries were again extended, and three research vessels have been operating full-time on exploratory and general biological work, and a fourth for some three months. The nature and scope of the research work of the Division of Food Preservation and Transport have recently been reviewed and, in view of the shortage of both staff and accommodation, it is being curtailed in extent. The anaerobic destruction of ascorbic acid is being investigated, the factors which govern the stability of type-A botulinum toxin when heated in canned vegetables have been eluci. dated, and an investigation of the factors affecting the germination of heat-resistant spores has been resumed. The canning of vegetables and fruit has continued to receive attention, and the causes of bitterness in fruit juices have been investigated, as well as the effect of sulphonated oils, fatty-acid esters, sulphated fatty-acid esters and wetting-agents in drying sultanas.

The Division of Forest Products has directed special attention to the problem of waste of timber; but much more knowledge is required of the basic chemical, physical and mechanical properties of Australian woods before the problem as a whole is solved. More than four thousand inquiries for information were received by this Division during the year, and the co-operative research scheme with the paper companies functioned smoothly and effectively. A technique developed for examining the living content of ray cells in material specially fixed immediately after felling has shown that timbers may fall into three classes. Growth studies on Eucalyptus gigantea and on siliceous inclusions in timber continued, as did studies on lignin and related compounds, wood carbohydrates and the alkaline hydrolysis of holocellulose. The Building Research Section reports steady progress in existing investigations, but work on architectural acoustics was the only new project of importance. Among the activities of the Wool Textile Research Section may be men. tioned the investigations of methods of forming vinyl polymers in wool and of the properties of the treated fibres, of the mode of formation of keratin and other constituents of the wool root, and the fractionation and characterization of extracellular mould enzymes. In addition to research on flax processing, work is in progress on the spinning, bleaching and weaving of flax yarns, while that on the bacteria responsible for water-retting promises substantial improvements in water-retting in Australia.

Some improvement in the staff conditions has been reported by the Division of Industrial Chemistry, but work generally has continued on the same lines as in the previous year. Electron-microscopical studies on biological problems of importance in medical and veterinary science and in industry have been undertaken, including a study of secondary phenomena in electron diffraction, and work is in progress on a new method of separation based on selective adsorption. Ore-dressing work has been carried out at Kalgoorlie 
and at Melbourne, and the reason for the interference of calcium ions in the flotation of topaz has been determined. In the field of physical metallurgy the fabrication of titanium, the effect of small additions of other elements on the structure and mechanical behaviour of lead, and the strength and structure of metals are the chief problems to receive attention.

The Division of Metrology has been rearranged into standards, research and test work, with very good results, while, in addition to maintaining the Commonwealth standards of measurement of heat and light and associated quantities and the primary electrical standards, the Division of Physics has undertaken major projects in the study of phenomena associated with precipitation and the installation of equipment for research at very low temperatures and in solar physics. In the Division of Electrotechnology a separate mathematical section has been formed, and the measuring facilities of the Division have been extended. Significant advances have been made in investigating the relation between molecular structure and dielectric properties. Continuing and extending the work of the previous year, the Division of Radiophysics has concentrated attention on fundamental studies of the radio-frequency radiation from the sun and the galaxy, the application of radar techniques to the study of natural and artificial rain formation, electronic methods of solving mathematical problems, and radio and radar methods of navigation and surveying. Plans for the work of the Meteorological Physics Section have been broadly determined, and theoretical and practical studies of the movement and behaviour of pressure systems continued, as well as experiments on the artificial stimulation of rainfall by the dry-ice process.

The Organisation is co-operating with the University of Melbourne in a programme of research on nuclear physics and cosmic rays under the direction of Prof. L. H. Martin, and has aimed at a study of the forces within the nucleus of the atom. Cooperative investigations on cosmic rays are also being undertaken with the University of Tasmania. Tracerelement investigations have been extended, but arrangements have been made to obtain supplies of radioactive isotopes from overseas and to develop a service for their handling by, and distribution to, research workers in Australia.

\section{GOVERNMENT RESEARCH IN NEW ZEALAND}

\section{ANNUAL REPORT OF THE DEPARTMENT OF SCIENTIFIC AND INDUSTRIAL RESEARCH}

$\mathrm{T}$ HE twenty-third annual report of the Depart. ment of Scientific and Industrial Research, New Zealand, covering the year ended March 31, 1949*, includes the Minister's statement, the Secretary's report, and reports from the branches, divisions and research committees or research associations, as well as from the university colleges and the Cawthron Institute. Results during the year came from an aggregate of small achievements in many fields rathor than from a few outstanding developments, and the demands made on the Department for assistance were greater than its resources and accommodation

* New Zealand. Twenty-third Annual Report of the Department of Seientific and Industrial Research. Pp. 88. (Wellington: Government Printer, 1949.) 18. $9 d$. could meet. The departmental organisation was arranged to provide for co-operative attack on problems by men of science trained in different techniques, and every effort was made to shorten the time-lag between the attainment of useful results and their being put into practice. Full use was made of the help available from the presence in New Zealand of some two hundred overseas scientific workers attending the Seventh Pacific Science Congress, and the exchange of ideas during the Congress made a great contribution to New Zealand's scientific effort.

Intensive work on improvement in the quality of pastures for all types of country led to improved strains of rye-grass and cocksfoot which were proved during the year. Prolonged tests on these and on clovers showed that the research work has yielded strains which under New Zealand conditions give marked increases in food values compared with the best selections from other countries. Progress was made towards an understanding of the response of pasture to top-dressing with phosphates, nitrogen and potash, and an entirely new view of nitrogen intake by the grazed pasture plant and its use in the leaf had to be adopted. Advances are also reported in the knowledge of methods for improving pasture in the hill country of both Islands, and plant-breeding work led to improved quality in stock fodder crops such as swedes, kale and lupins. An intensive programme of research on insect pests and fungus, bacterial and virus diseases of all farm crops was maintained, while, after exhaustive tests, three new varieties of apple of English origin and five varieties of peaches from Australia were selected for issue to New Zealand growers. Plant-breeding work at the Wheat Research Institute promised to afford varieties superior even to Hilgendorf in quality.

The Plant Chemistry Laboratory, besides working out two methods for determining minute amounts of weedkillers of the hormone type, also had a pilotscale fermentation plant which could be utilized for practically any type of industrial fermentation and was studying the antagonistic properties of endemic species of Polyporacer and of Actinomycetes from soil samples of varied origin. The recently established Hop Research Station did much useful preliminary work, and the Dairy Research Institute, which in 1947 ceased to be a unit of the Department, continued to work on similar lines and developed on a commercial scale the system of pressing and wrapping cheese in 'Pliofilm'. Much assistance was rendered by the Department and the Cawthron Institute to the tobacco industry, and the Dominion Laboratory undertook a growing volume of research work for industry, including some of the difficult new methods where radioactive isotopes are used.

The Auckland Industrial Development Laboratories and the Canterbury College Industrial Development Department continued to provide valuable assistance to State Departments as well as to industry, as did the Dominion Physical Laboratory, where a laboratory for electron microscopy to serve all research workers in New Zealand was established. An electrical-resistance type of thermometer was in the process of being developed with the object of devising a reliable temperature alarm to protect fruit growers from serious losses due to frosts. At the request of the Dominion Observatory a quartzcrystal-controlled electric clock was built to operate from a battery supply, and an automatic exposure. timer for use in X-radiography and photofluorography 